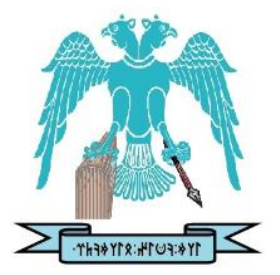

JOURNAL OF ENERGY SYSTEMS

$2020,4(2)$

\title{
Speed control of permanent magnet synchronous motor using neural network model predictive control
}

\author{
Venkatesan S. (D) \\ Anna University, Department of Electrical and Electronics Engineering, Tamil Nadu, India, \\ venkatesanauc@gmail.com \\ Premkumar Kamaraj \\ Rajalakshmi Engineering College: Chennai, Tamil Nadu, India, premkumar.k@ rajalakshmi.edu.in
}

M. Vishnu Priya

Saveetha School of Engineering, Department of Electrical and Electronics Engineering, Tamil Nadu, India, vish0790@gmail.com

\begin{abstract}
Model predictive control has been widely used in the industry. This can control the multivariable system with constraints on input and output variables but it needs online computation solver, and creates the nonconvex solution in nonlinear plant due to the parameter uncertainties. The online computational problem and non-convex solution of the model predictive control are achieved via neural network model predictive control. The paper explores the speed control of permanent magnet synchronous motor (PMSM) by using neural network model predictive control (NNMPC) technique. The multi-layer artificial neural network is used to identify the dynamics of PMSM. The set point speed tracking control of PMSM is identified by using neural network model predictive control strategy. By using the set of input and output data obtained from the system, the multi input-output feed-forward neural network model is created. Levenberg-Marquardt algorithm is used to train the process models of the PMSM. That provides future plant output for control optimization of the predictive control. The overall system is developed and tested in the MATLAB/Simulink. To evaluate the efficiency of the controller proposed, it is compared with a constrained model predictive controller through the studies of simulation. The overshoot and settling time of the speed response of the PMSM are measured and analyzed for NNMPC and constrained MPC.
\end{abstract}

Keywords: Neural network, Permanent magnet, Predictive controller, Synchronous motor

Venkatesan S., Kamaraj, P., \& Vishnu Priya, M., Speed control of permanent magnet synchronous Cite this paper as: $\quad$ motor using neural network model predictive control. Journal of Energy Systems 2020, 4(2), 7187, DOI: $10.30521 /$ jes.727975

(C) 2020 Published by peer-reviewed open access scientific journal, JES at DergiPark (https://dergipark.org.tr/en/pub/jes)

\begin{tabular}{r|l} 
Nomenclature & \\
\hline $\mathrm{R}_{\mathrm{s}}$ & Stator Resistance $(\Omega)$ \\
$\mathrm{L}_{\mathrm{d}}$ & Direct axis stator inductance $(\mathrm{H})$ \\
$\mathrm{L}_{\mathrm{q}}$ & Quadrature axis stator inductance $(\mathrm{H})$ \\
$\mathrm{V}_{\mathrm{d}}$ & Direct axis voltage $(\mathrm{V})$ \\
$\mathrm{V}_{\mathrm{q}}$ & Quadrature axis voltage $(\mathrm{V})$ \\
$\mathrm{i}_{\mathrm{d}}$ & Direct axis stator current $(\mathrm{A})$ \\
$\mathrm{i}_{\mathrm{q}}$ & Quadrature axis stator current $(\mathrm{A})$ \\
$\omega_{\mathrm{e}}$ & Electrical Speed $(\mathrm{rad} / \mathrm{s})$ \\
$\varphi_{\mathrm{mg}}$ & Flux linkage due to permanent magnet $(\mathrm{Wb}-\mathrm{t})$ \\
$\mathrm{Z}_{\mathrm{p}}$ & Number of pole pairs \\
$\mathrm{J}_{\mathrm{m}}$ & Moment of inertia $\left(\mathrm{kg} \mathrm{m}^{2}\right)$ \\
$\mathrm{T}_{\mathrm{e}}$ & Electromagnetic Torque $(\mathrm{N}-\mathrm{m})$ \\
$\mathrm{B}_{\mathrm{v}}$ & Viscous coefficient \\
$\mathrm{T}_{\mathrm{L}}$ & Load Torque (N-m) \\
\hline \hline
\end{tabular}




\section{INTRODUCTION}

Permanent magnet synchronous motor (PMSM) is broadly utilized in electric vehicle and modern applications because of its high-energy efficiency, torque density and low weight [1-3]. PMSM is driven with solid-state drives, which have been a field of passion for researchers throughout the previous two decades. Different control techniques applied for PMSM are found in the literature. Most of the control techniques are based on the classical d-q model and it is known as field-oriented control (FOC) [4]. Rotor position control along with speed control objective of the PMSM was achieved by cascade control structure [5]. Current control along with speed control objective of the PMSM was achieved by double loop feedback control. In double loop feedback control, the outer-loop used for control the angular velocity of the PMSM and inner loop control used for control the q-axis current of the PMSM [6]. In the implementation of FOC of PMSM, the rotor position is mandatory to achieve desired performance in the motor and for this purpose, rotor position sensors are installed in the PMSM, which increases the cost. To overcome this problem, sensor less vector control methods were introduced and along with these back-stepping methods, sliding mode control and fuzzy controller are mentioned in the literature [7-9]. However, these approaches have problem due to constraints of the PMSM. It is hard to understand the advantages of optimal control of the system with a nonlinear behavior of the PMSM system and adherence of constraints on the manipulated variable, state variables, and output variables. In this case, it is not possible to derive mathematical equations for the PMSM system.

Linear Model Predictive Controller (MPC) has become a suitable control of a technique used in the industry with the account of constraints handling. For handling nonlinear process, MPC requires large computational capacity and nonlinear solver. Some researchers combined the linear predictive control with nonlinear optimization techniques to solve the nonlinear process but that increased the online computation time and the system generated the non-convex solution due to parameter uncertainties. Moreover, this type of control needs mathematical model of the plant. To overcome, online computation burden and non-convex solution, in this paper, neural network model predictive control is introduced for the speed control of permanent magnet synchronous motor. The neural network model predictive control does not require any mathematical model of the system, plant model is updated in offline mode by using the collected data from the plant and it reduces the online computation burden [10-12]. The neural network model predictive control technique has two processes, the first process is plant identification and the second process is predictive control mechanism using receding horizon policy [13-15].

In this paper, MPC and Neural Network Model Predictive Control (NNMPC) are applied to control the speed of the permanent magnet synchronous motor. Comparative analysis between MPC and NNMPC for different operating conditions of the PMSM are presented to test the effectiveness of the NNMPC. The organization of the paper as follows: The state space model of the PMSM is described in the section 2. Section 3 explains about model predictive control for the PMSM. Section 4 explains about neural network model predictive control for the PMSM. The simulation results are discussed in the section 5. Concluding remarks are given in the section 6 .

\section{STATE MODEL OF PMSM}

The first and foremost job is to find a linear model of the permanent magnet synchronous motor from the differential equations of the plant [16-18]. The differential equations for the PMSM in $d$ - $q$ reference frame is given by the following equations, 


$$
\begin{gathered}
\frac{d i_{d}(t)}{d t}=\frac{1}{L_{d}}\left[v_{d}(t)-R_{s} i_{d}(t)+\omega_{e}(t) L_{q} i_{q}(t)\right] \\
\frac{d i_{q}(t)}{d t}=\frac{1}{L_{d}}\left[v_{q}(t)-R_{s} i_{q}(t)+\omega_{e}(t) L_{d} i_{d}(t)-\omega_{e}(t) \varphi_{m g}\right] \\
\frac{d \omega_{e}(t)}{d t}=\frac{Z_{p}}{J_{m}}\left[T_{e}-\frac{B_{v}}{Z_{p}} \omega_{e}(t)-T_{L}\right] \\
T_{e}=\frac{3}{2} Z_{p}\left[\varphi_{m g} i_{q}+\left(L_{d}-L_{q}\right) i_{d}(t) i_{q}(t)\right]
\end{gathered}
$$

There are three bilinear terms in the differential equations of the PMSM i.e., $\omega_{e}(t) i_{q}(t), \omega_{e}(t) i_{d}(t)$ and $i_{d}(t) i_{q}(t)$. Using Taylor series expansion, the aforementioned bilinear terms are approximated around the operating points $\mathrm{i}_{\mathrm{d}}^{0}, \mathrm{i}_{\mathrm{q}}^{0}$ and $\omega_{\mathrm{e}}^{0}$ to obtain its linear approximation. On substituting these approximations in Eq. (1) and Eq. (2), we obtain the linearized model of plant in the following form:

$$
\begin{gathered}
\frac{d X(t)}{d t}=A \cdot X(t)+B \cdot u(t)+\mu^{0} \\
y(t)=C \cdot X,
\end{gathered}
$$

where,

$$
\begin{gathered}
X(t)=\left[\begin{array}{c}
i_{d}(t) \\
i_{q}(t) \\
\omega_{e}(t)
\end{array}\right] \\
u(t)=\left[\begin{array}{l}
v_{d}(t) \\
v_{q}(t)
\end{array}\right] \text { and } y(t)=\left[\begin{array}{l}
i_{d}(t) \\
\omega_{e}(t)
\end{array}\right]
\end{gathered}
$$

State matrix A is given by,

$$
A=\left[\begin{array}{ccc}
-\frac{R_{s}}{L_{d}} & \frac{L_{q}}{L_{d}} \omega_{e}^{0} & \frac{L_{q}}{L_{d}} i_{q}^{0} \\
-\frac{L_{d}}{L_{q}} \omega_{e}^{0} & -\frac{R_{s}}{L_{q}} & -\left(\frac{L_{d}}{L_{q}} i_{d}^{0}+\frac{\varphi_{m g}}{L_{q}}\right) \\
0 & \frac{3 Z_{p}^{2} \varphi_{m g}}{2 J_{m}} & -\frac{B_{v}}{J_{m}}
\end{array}\right]
$$

input matrix B is given by,

$$
B=\left[\begin{array}{cc}
\frac{1}{L_{d}} & 0 \\
0 & \frac{1}{L_{q}} \\
0 & 0
\end{array}\right]
$$

and output matrix $\mathrm{C}$ is given by,

$$
C=\left[\begin{array}{lll}
1 & 0 & 0 \\
0 & 0 & 1
\end{array}\right]
$$




$$
\mu^{0}=\left[\begin{array}{c}
-\frac{L_{q}}{L_{d}} \omega_{e}^{0} i_{q}^{0} \\
\frac{L_{d}}{L_{q}} \omega_{e}^{0} i_{d}^{0} \\
-\frac{Z_{p} T_{L}}{J_{m}}
\end{array}\right]
$$

$\mu^{0}$ is an input disturbance vector consists of load torque and steady-state parameters. The aim of the developed controller is to track the set speed at the same time controller should maintain direct axis current $\left(\mathrm{i}_{\mathrm{d}}\right)$ is zero and maintain the direct axis voltage and quadrature axis voltage at prescribed values. Hence, from state-space formulation, electrical speed $\left(\omega_{\mathrm{e}}\right)$ and direct axis current are considered as outputs. The $\mathrm{i}_{\mathrm{q}}$ current is one of the variables of state that will be evaluated during implementation.

\section{Conversion of Continuous-Time Model to discrete time model}

With the zero-order hold mechanism, we can develop discrete time model of Eq. (5) and Eq. (6) which describe the dynamics [19]-[21]. By considering $t_{0}=0, t_{1}=\Delta t, t_{2}=2 \Delta t, \ldots, t_{i}=i . \Delta t$ is the sampling time with a fixed sampling time $\Delta t$ and sampling index $i$. The systematic solution of the differential equation at time $t_{l}=\Delta t$ is obtained by the Eq. (13),

$$
x_{m}\left(t_{1}\right)=e^{A_{m} \Delta t} x_{m}(0)+\int_{0}^{\Delta t} e^{A_{m}(\Delta t-\tau)} B_{m} u(\tau) d \tau+\int_{0}^{\Delta t} e^{A_{m}(\Delta t-\tau)} \mu^{0} d \tau
$$

With the initial condition vector $\mathrm{x}_{\mathrm{m}}\left(\mathrm{t}_{1}\right)$, the differential equation analytical solution at time $\mathrm{t}_{2}$ is obtained by means of following expression,

$$
x_{m}\left(t_{2}\right)=e^{A_{m} \Delta t} x_{m}(t 1)+\int_{\Delta t}^{2 \Delta t} e^{A_{m}(2 \Delta t-\tau)} B_{m} u(\tau) d \tau+\int_{\Delta t}^{2 \Delta t} e^{A_{m}(2 \Delta t-\tau)} \mu^{0} d \tau
$$

The analytical solution of $x_{m}\left(t_{i}\right)$ is given by the initial condition vector $x_{m}\left(t_{i-1}\right)$ for an arbitrary time $t_{i}=$ i. $\Delta \mathrm{t}$.

$$
x_{m}\left(t_{i}\right)=e^{A_{m} \Delta t} x_{m}\left(t_{i-1}\right)+\int_{(i-1) \Delta t}^{i \Delta t} e^{A_{m}(i \Delta t-\tau)} B_{m} u(\tau) d \tau+\int_{(i-1) \Delta t}^{i \Delta t} e^{A_{m}(i \Delta t-\tau)} \mu^{0} d \tau
$$

The convolution integral is cut down as the activation input $u(\tau)$ is excluded from the accumulation and the following integral equality is shown to hold,

$$
\int_{(i-1) \Delta t}^{i \Delta t} e^{A_{m}\left(i \Delta t-\tau^{\prime}\right)} d \tau^{\prime}=\int_{0}^{\Delta t} e^{A_{m} \tau} d \tau
$$

By substitution $i^{*} \Delta t-\tau^{\prime}=\tau$ in the Eq. (16) and it is converted into discrete time model with integral equality and zero-order hold and it is expressed as follows,

$$
x_{m}\left(t_{i}\right)=e^{A_{m} \Delta t} x_{m}\left(t_{i-1}\right)+\int_{0}^{\Delta t} e^{A_{m} \tau} d \tau B_{m} u\left(t_{i-1}\right)+\int_{0}^{\Delta t} e^{A_{m} \tau} d \tau \mu^{0}
$$

Let $A_{d}$ and $B_{d}$ denotes discrete time system matrices,

$$
A_{d}=e^{A_{m} \Delta t} ; \quad B_{d}=\int_{0}^{\Delta t} e^{A_{m} \tau} d \tau B_{m}
$$


and $\mu^{d}$ denotes discrete time constant vector,

$\mu^{d}=\int_{0}^{\Delta t} e^{A_{m} \tau} d \tau \mu^{0}$

The compact equation of the discrete-time model (i.e. Eq. (17)) is expressed in the following Eq. (18) as,

$$
x_{m}\left(t_{i}\right)=A_{d} x_{m}\left(t_{i-1}\right)+B_{d} u\left(t_{i-1}\right)+\mu^{d}
$$

The output $y\left(t_{i}\right)=C_{d} x_{m}\left(t_{i}\right)$, where $C_{d}=C_{m}$. Eq. (19) can also be explained in terms of a forecast one step ahead as,

$$
x_{m}\left(t_{i+1}\right)=A_{d} x_{m}\left(t_{i}\right)+B_{d} u\left(t_{i}\right)+\mu^{d}
$$

In the discrete-time model, the constant vector $\mu^{0}$ is the function of input disturbance. This discrete-time model is used for the design of model predictive control and neural network model predictive control of PMSM. In next section, model predictive controlled PMSM is explained.

\section{MODEL PREDICTIVE CONTROL}

Model Predictive Control (MPC) is used in the industry due to advanced process control strategy. Model predictive controller depends on dynamic model of the process system and online optimization solver [22]-[30]. Fig. 1 shows the model predictive controller for permanent magnet synchronous motor (PMSM).

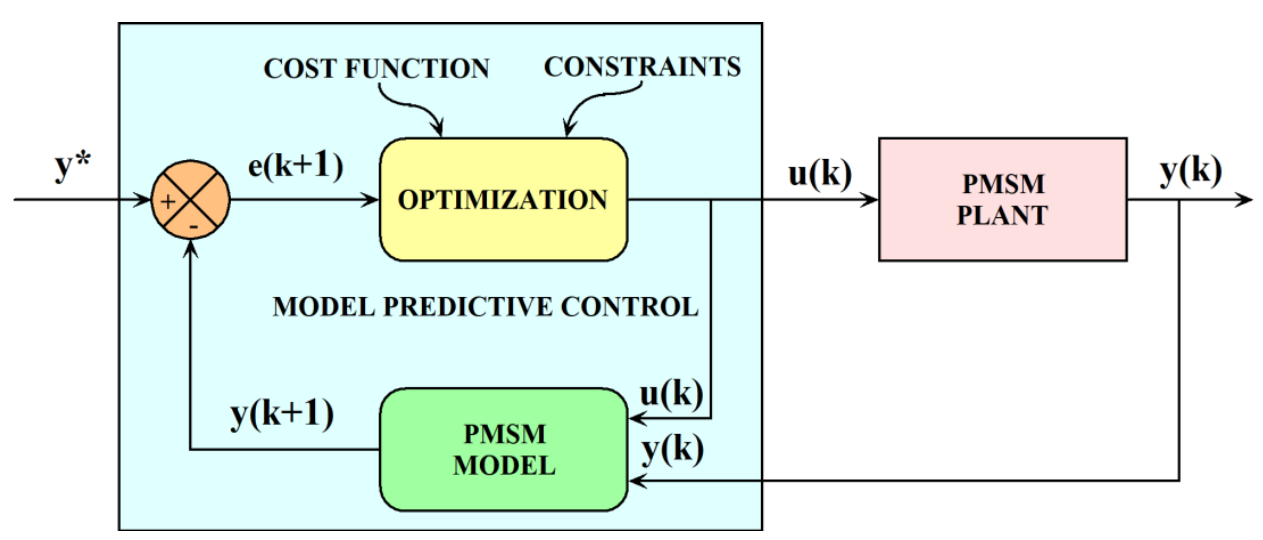

Figure 1. Model predictive controlled PMSM

The PMSM plant output $y(k)$ should track the reference command signal $y^{*}$. This can be attained by, comparing predicted output from PMSM model $y(k+1)$ with reference command $y^{*}$, and calculating the input $u(k)$ based on cost function and constraints optimization. The model predictive controller also has to ensure that the constraints are met for all times. In this method, control objectives are converted into cost function, which maps future states, outputs and controlled variables sequences into a scalar cost value. The cost function facilitates to generate control input for the PMSM plant based on the predicted values and reference command signal. The const function used in the model predictive controller to track the reference command is given in the Eq. (20),

$$
J=\sum_{i=N_{1}}^{N_{2}}\left[y(k+i)-y^{*}(k+i)\right]^{2}+\lambda \sum_{i=1}^{N_{u}} \Delta u^{2}(k+i-1)
$$


With the following conditions,

$\Delta u(k+i-1)=0$

$1 \leq N_{u}<i \leq N_{2}$

where, $N_{u}$ - the control horizon, $N_{1}$ - minimum prediction horizon and $N_{2}$ - maximum prediction horizon, $i$ - is the order of the predictor, $y^{*}$ - reference command, $\lambda$ - weight factor, $\mathrm{k}$-time step and $\Delta$ differentiation operator. The control input signal ' $u$ ' is subjected with following constraints,

$u_{\min } \leq u(k+i) \leq u_{\max }$

where, $i=1,2,3, \ldots N_{u}$

Based on these two arguments and by using the internal dynamic system model, the future states and controlled variables can be predicted over the prediction horizon and cost function is minimized accordingly.

\subsection{Optimization Stage}

By minimizing the objective function subject to both the evolution over the prediction horizon of the discrete-time internal system model, the constraints give a rise to a constrained problem of optimal control over the finite-time. The consequence statement is the optimal sequence of controlled variables, $u_{\text {opt }}(k)$ :

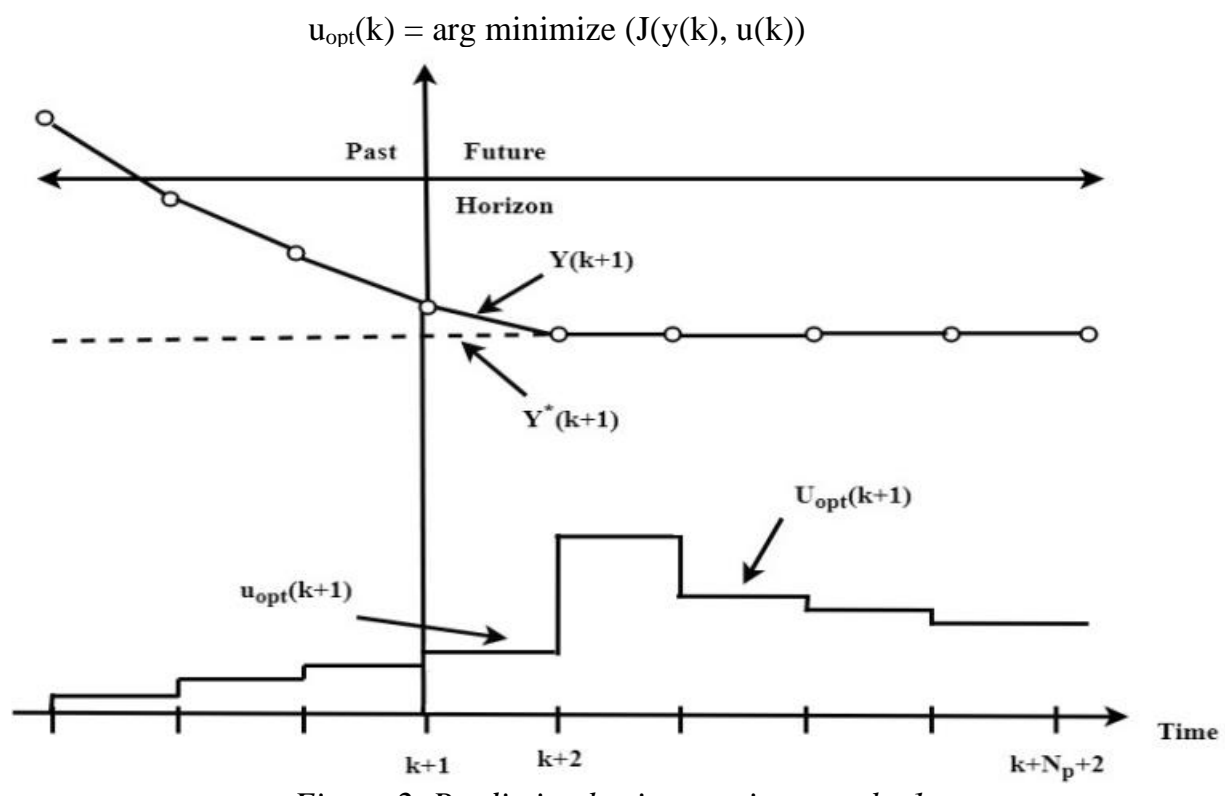

Figure 2. Prediction horizon at time step $k+1$

\subsection{Receding Horizon Policy}

The solution to the optimization problem Eq. (21) yields at time step $k\left(t=k T_{S}\right)$. An open-loop optimal sequence of control input variables $u_{\text {opt }}(k)$ from time step $k$ to $k+N p-1$. To provide feedback, Only the first element of that series is applied to the method, namely $u_{\text {opt }}(k)$. In the next step $k+1$ a new state estimate is obtained and the problem of optimization is solved over the relocated horizon from $k+1$ to $k+N_{p}$ again. This policy is named as receding horizon control and it is illustrated in Fig. 2. The efforts to formulate MPC control problems is often quite small, while the efforts to resolve the underlying optimization problem are discouraging. Unfortunately, the computational burden related to solving the 
optimization problem underlying MPC increases exponentially with the length of the prediction horizon and plant model inside the MPC is updated at every step time $k$ to predict the accurate output from the plant i.e., plant model should be updated regularly if any parameter uncertainties occur in the plant. To overcome these problems, neural network model predictive controller is developed for speed control of PMSM and details are provided in the next section.

\section{NEURAL NETWORK MODEL PREDICTIVE CONTROL}

Linear predictive control performance is very poor when applied to complex non-linear plant. This problem can be overcome by combining predictive control with non-linear online optimization techniques but it has some disadvantages such as nonlinear online optimization takes more time to predict the optimal control input and also solution may be non-convex due to parameter uncertainties. Moreover, this nonlinear predictive control needs mathematics of the plant to provide optimum results. To overcome these problems, in this work neural network model predictive control is proposed for the speed control of permanent magnet synchronous motor. It does not required mathematical model of plant, neural network is trained in offline mode without mathematical model and it overcome the problem of parameter uncertainties [31]-[43]. The neural network model predictive controller is designed by the following two-step, plant identification using neural network is done in step one and predictive control action using receding horizon policy is done in step two. Fig. 3 shows the PMSM plant identification by neural network.

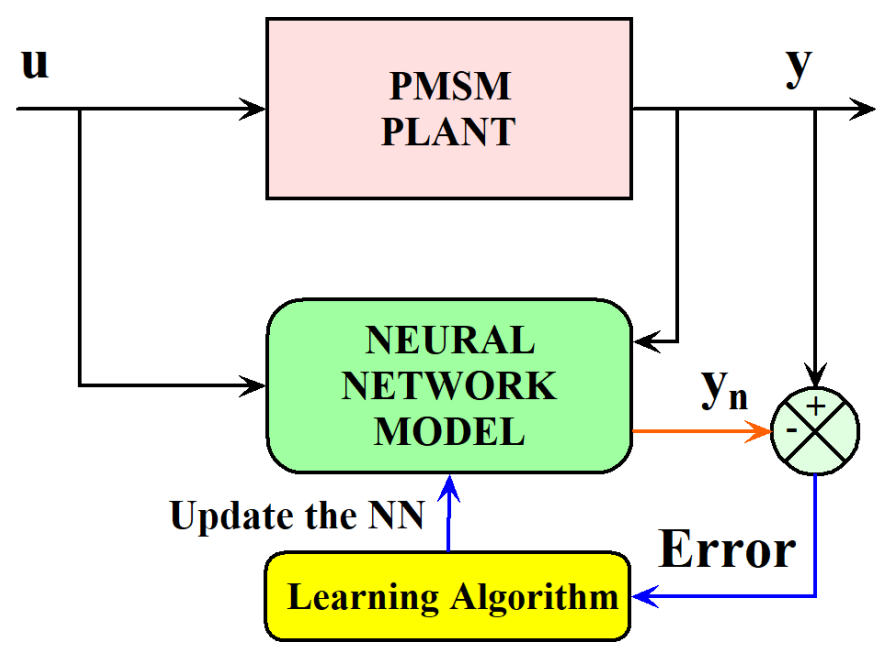

Figure 3. PMSM plant identification by neural network.

The input-output data of the open loop operation of the PMSM are collected and it is used train the neural network using learning algorithm. The learning algorithm updates the weights of the neural network to minimize the following objective function,

$$
J_{N N}=\sqrt{\frac{\sum_{i=1}^{n}\left(y_{i}-y_{n_{i}}\right)^{2}}{n}}
$$

Where, $y_{i}$ is the plant output data, $\mathrm{y}_{\mathrm{ni}}$ is the output from the neural network and $n$ is the total number of data set used for training. The structure of the neural network plant model is shown in the Fig. 4. 


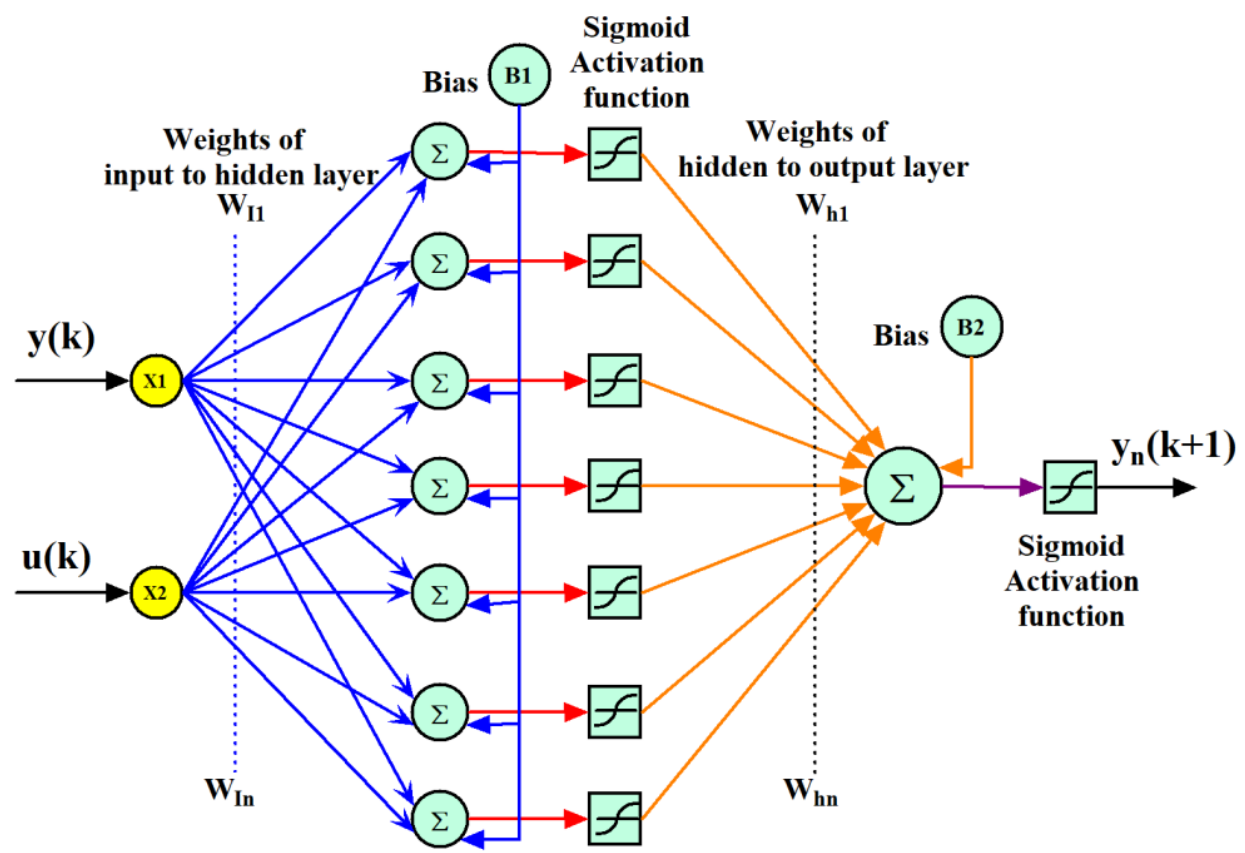

Input Layer

Hidden Layer

Output Layer

Figure 4. Structure of Neural Network Plant model

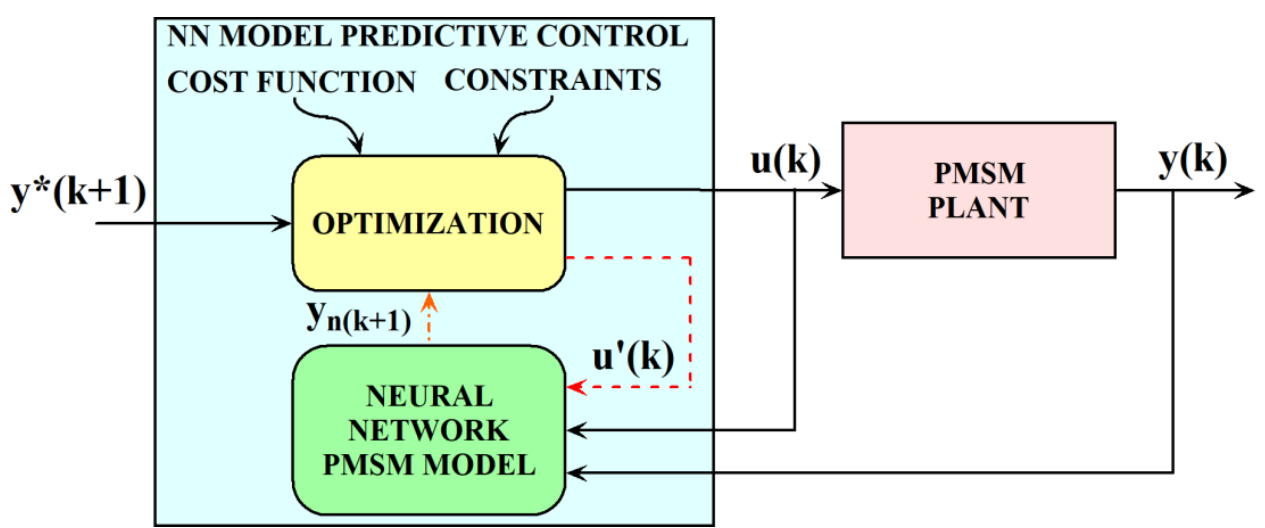

Figure 5. Neural Network Model Predictive Controlled PMSM

Neural network model predictive controlled PMSM is shown in Fig. 5. Neural network PMSM model is created by plant identification to predict future plant performance. Based on previous control input $(\mathrm{u}$ (k)) and output (y (k)) of the PMSM plant, neural network plant model predicts the future plant output $\left(\mathrm{y}_{\mathrm{n}}(\mathrm{k}+1)\right)$. The controller then calculates the manipulated vector ' $\mathrm{u}(\mathrm{k}+1)$ ' which is used to control the plant output over a given future time horizon. To generate the optimum control input to the PMSM plant, the following objective function is minimized using numerical optimization,

$$
J_{N N M P C}=\sum_{j=N 1}^{N 2}\left(y^{*}(k+j)-y_{n}(k+j)^{2}+\eta \sum_{j=1}^{N_{u}}\left(u^{\prime}(k+j-1)-u^{\prime}(k+j-2)\right)^{2}\right.
$$

Where, $N_{u}$ - the control horizon, $N_{l}$ - minimum prediction horizon and $N_{2}$ - maximum prediction horizon, $j$ - is the order of the predictor, $y^{*}$ - reference command, $y_{n^{-}}$output from neural network, $\eta-$ weight factor, $k$-time step and $u^{\prime}$ - control input signal for plant from control optimization. In next section, simulation result of the classical model predictive controlled PMSM and neural network model predictive controlled PMSM is discussed. 


\section{SIMULATION RESULTS}

In this section, simulation of the speed control of permanent magnet synchronous motor with classical model predictive controller and neural network model predictive controller is discussed. The specification of the permanent magnet synchronous motor is shown in Table 1.

Table 1. Specification of PMSM

\begin{tabular}{lll}
\hline Description & Symbol & Value \\
\hline Sampling interval & $\Delta \mathrm{t}$ & $200 \mu \mathrm{s}$ \\
Direct and Quadrature axis inductance & $\mathrm{L}_{\mathrm{d}}$ and $\mathrm{L}_{\mathrm{q}}$ & $7 \mathrm{mH}$ \\
Total inertia & $\mathrm{J}_{\mathrm{m}}$ & $0.00004 \mathrm{~kg} . \mathrm{m} 2$ \\
Viscous coefficient & $\mathrm{B}_{\mathrm{v}}$ & $0.00011 \mathrm{Nm} . \mathrm{s}$ \\
Resistance & $\mathrm{R}_{\mathrm{s}}$ & $2.98 \Omega$ \\
Total pole pairs & $\mathrm{Z}_{\mathrm{p}}$ & 2 \\
Linkage Flux & $\Phi_{\mathrm{mg}}$ & $0.125 \mathrm{wb}$ \\
\hline
\end{tabular}

\subsection{Constraints of the PMSM}

The maximum voltage of the PMSM drive is determined by the voltage of the DC bus $\left(\mathrm{V}_{\mathrm{dc}}\right)$ and the modulation value of the PWM. The linear modulation range limits the maximum possible voltage amplitudes, so that;

$$
\sqrt{v_{d}^{2}+v_{q}^{2}} \leq \frac{V_{d c}}{\sqrt{3}}
$$

and therefore, this non-linear constraint can always be imposed by means of a rectangular area close to the circular area as,

$$
\begin{gathered}
\left|v_{q}\right| \leq \epsilon \frac{V_{d c}}{\sqrt{3}}, \\
\left|v_{d}\right| \leq \sqrt{\left(1-\epsilon^{2}\right)} \frac{V_{d c}}{\sqrt{3}},
\end{gathered}
$$

where, $0 \leq \epsilon \leq 1$. With $\epsilon=0.5$ and the input DC voltage is $\mathrm{V}_{\mathrm{dc}}=100 \mathrm{~V}$, the $\mathrm{V}_{\mathrm{q}}$ and $\mathrm{V}_{\mathrm{d}}$ constraints get the values,

$$
\begin{gathered}
-28.87 \leq V_{q} \leq 28.87 \\
-50 \leq V_{d} \leq 50
\end{gathered}
$$

The restrictions on incremental $V_{q}$ and $V_{d}$ modifications are enforced as,

$$
\begin{aligned}
& -10.0 \leq \Delta V_{q} \leq 10.0 \\
& -10.0 \leq \Delta V_{d} \leq 10.0
\end{aligned}
$$

The parameter used in the classical model predictive controller is given as; the control horizon $N_{C}$ is selected as 3, the prediction horizon $N_{P}$ is selected as 10 and sample time selected as 0.1. The Simulink model of the model predictive controlled PMSM is shown in Fig. 6. Manipulated variable taken as $q$ axis voltage of the PMSM and manipulated output taken as angular velocity of the PMSM. 


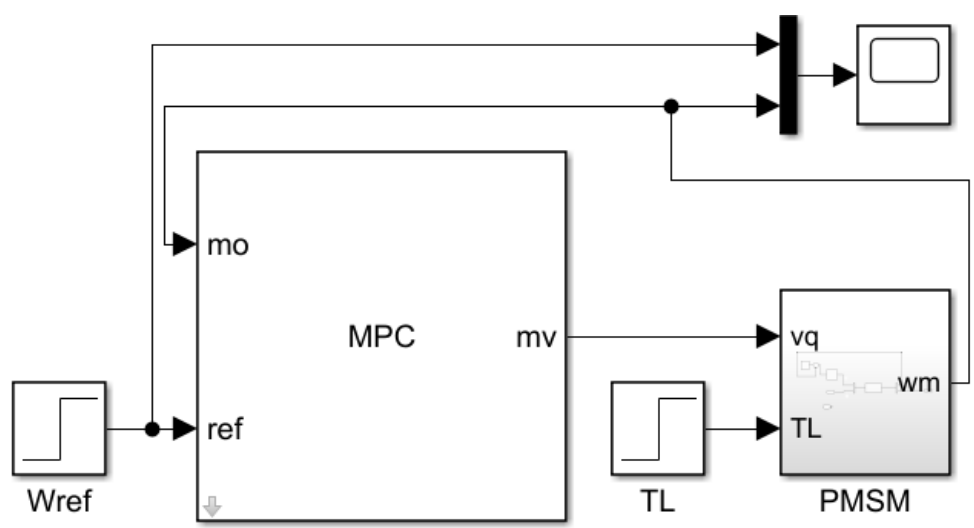

Figure 6. Simulink model of model predictive controlled PMSM

The parameter of the neural network model predictive controller is shown in Table 2. The Simulink model of the neural network model predictive controlled PMSM is shown in Fig. 7. Control signal taken as q-axis voltage of the PMSM and plant output taken as angular velocity of the PMSM.

Table 2. The NNMPC Parameters

\begin{tabular}{ll}
\hline Parameters & Values \\
\hline Cost horizon $\left(\mathrm{N}_{2}\right)$ & 7 \\
Control horizon $\left(\mathrm{N}_{\mathrm{u}}\right)$ & 2 \\
Number of hidden layers & 7 \\
Initial weights & 1 \\
Activation function & Sigmoidal \\
Epochs & 1000 \\
Training algorithm & Levenberg-Marquardt \\
Train samples & 1000 \\
Architecture & Feed forward \\
\hline
\end{tabular}

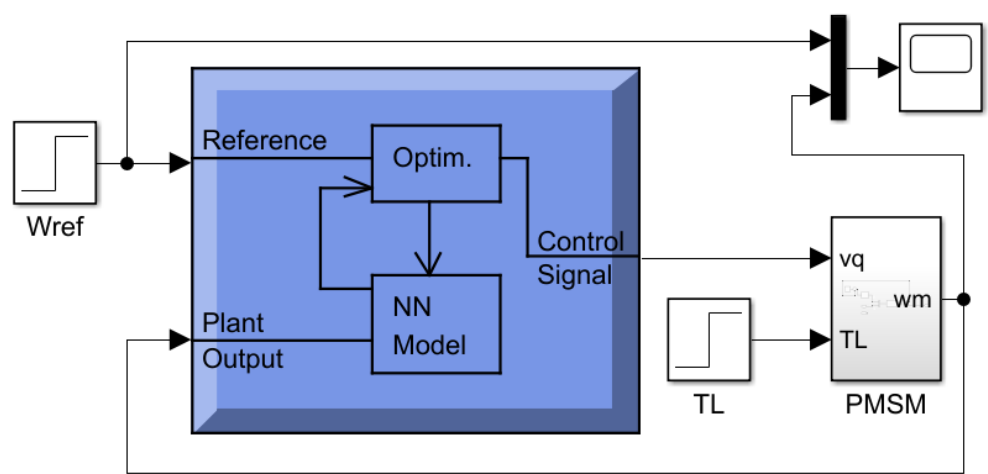

Figure 7. Simulink model of the neural network model predictive controlled PMSM

The following steps are used to design the neural network model predicative control in MATLAB. In the first step, opening interface of the neural network predictive control block is shown in Fig. 8(a). In this block, one has to enter the details of cost horizon, control horizon, control weight factor, search weight factor, minimization routine and iterations per sample. In the second step, open the plant identification window and it is shown in Fig. 8(b). In this block, one has to enter the detail of size of the hidden layer, sample interval, number of delayed plant input and outputs. Next process is to generate the training data using mathematical model of the plant or collected data from the plant and it is imported from import option of the plant identification block. After generation of the input and output data for 
the training, neural network is trained using Levenberg-Marquardt algorithm and training details are shown in Fig. 8(c).

The collected input and output data for training, neural network output and error during testing is shown in Fig. 9(a). The error between neural network and target is around \pm 0.1 only. One thousand iterations have been used for train the neural network and performance curve of the neural network training is shown in Fig. 9(b) and the mean squared error is found as 0.0003372 only. Regression analysis is preformed between neural network output and target data and it is shown in the Fig. 9(c). From the regression results, it is observed that both neural network output and target data are super imposed each other.

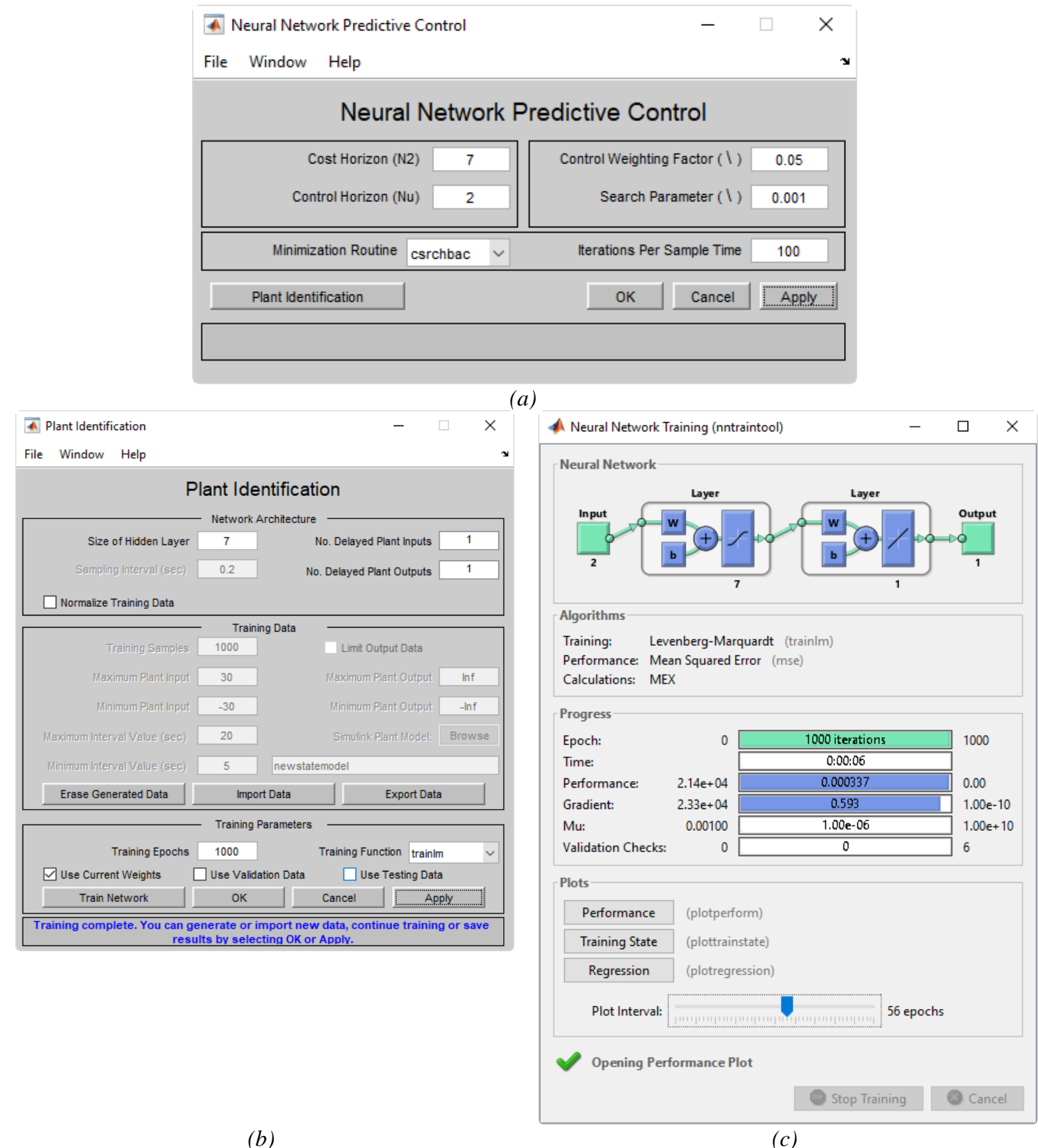

Figure 8. (a) Neural network model predictive control, (b) plant identification by NNMPC, (c) neural network training. 
The developed NNMPC and MPC controlled PMSM are tested with different operating conditions of the PMSM such as constant speed reference settings, varying set speed command and sudden load disturbance conditions. Fig. 10 depicts the set point tracking results of the PMSM for set speed command of $800 \mathrm{rpm}$. Model predictive controlled PMSM speed response has $12.5 \%$ overshoot and settled at 0.3 second. Neural network model predictive controlled PMSM speed response has $0.13 \%$ overshoot and settled at 0.035 seconds. From the test results, it is observed that neural network model predictive controller has better performance than MPC.
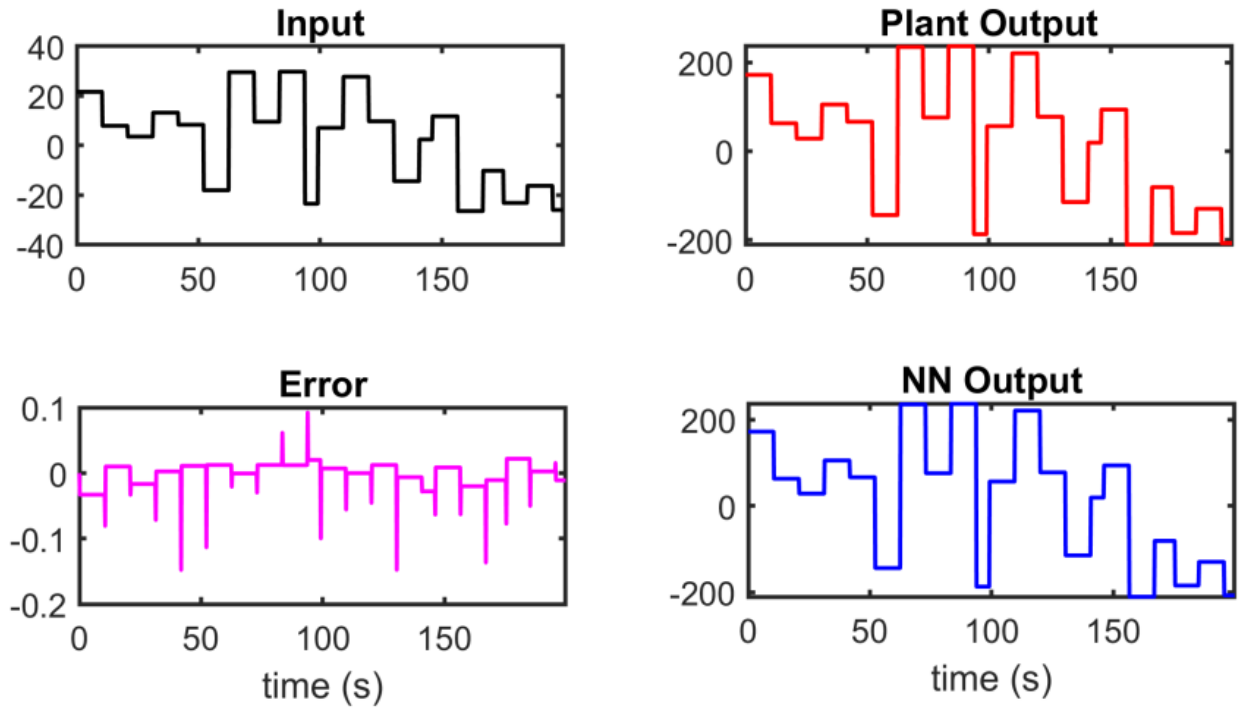

(a)
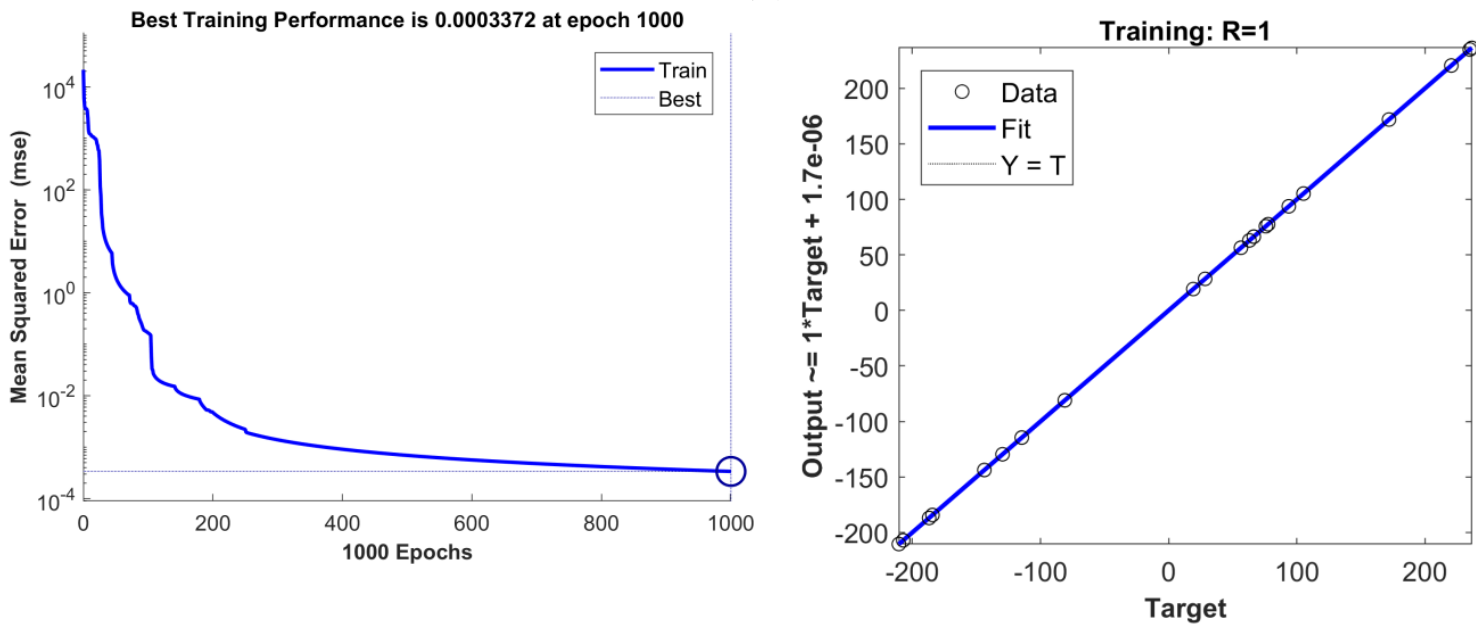

(b)

(c)

Figure 9. (a) Neural Network Model Predictive control training result (b) Performance plot (c) Regression result. 


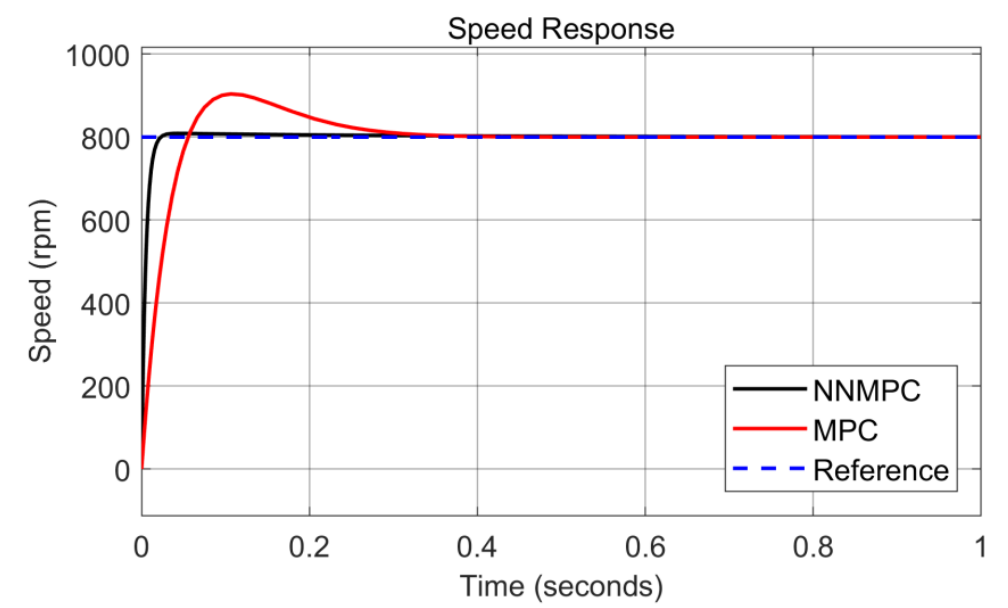

Figure 10. Speed response of the PMSM for constant set speed command

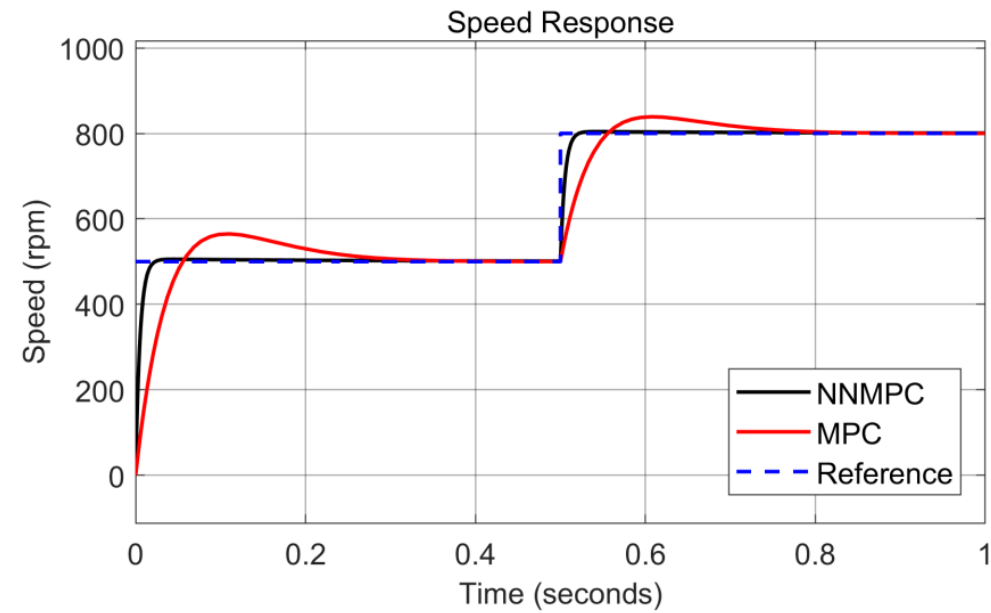

Figure 11. Speed response of the PMSM for speed reference change from $500 \mathrm{rpm}$ to $800 \mathrm{rpm}$

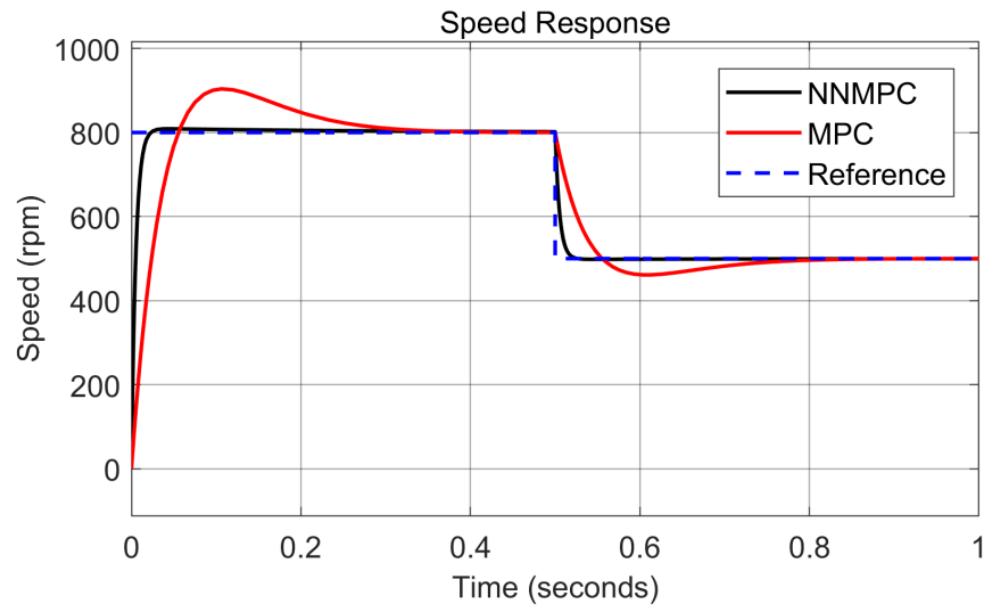

Figure 12. Speed response of the PMSM for speed reference change from $800 \mathrm{rpm}$ to $500 \mathrm{rpm}$ 


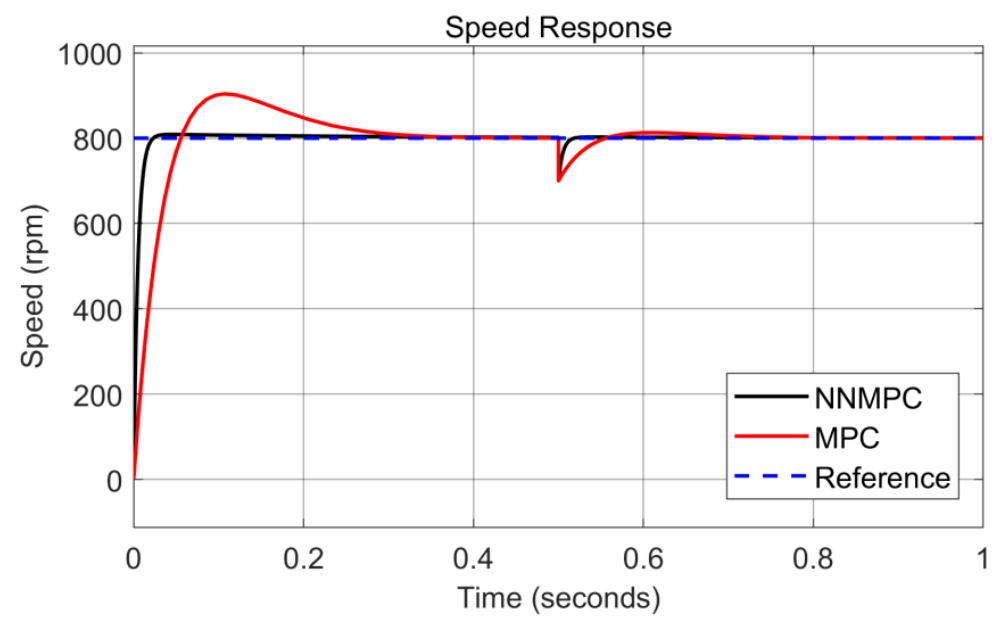

Figure 13. Speed response of the PMSM for sudden load change from $0 \mathrm{Nm}$ to $0.1 \mathrm{Nm}$

Fig. 11 shows the set point tracking results of the PMSM for speed reference change from $500 \mathrm{rpm}$ to $800 \mathrm{rpm}$ at 0.5 second. Model predictive controlled PMSM speed response has $6.25 \%$ overshoot, and settled at 0.75 second. Neural network model predictive controlled PMSM speed response has $0.11 \%$ overshoot and settled at 0.53 second. Fig. 12 shows the set point tracking results of the PMSM for speed reference change from $800 \mathrm{rpm}$ to $500 \mathrm{rpm}$ at 0.5 second. Model predictive controlled PMSM speed response has $4.3 \%$ undershoot, and settled at 0.77 second. Neural network model predictive controlled PMSM speed response has $0.12 \%$ undershoot and settled at 0.54 second. From the test results, it is observed that neural network model predictive controller has less overshoot, less undershoot and settled quickly.

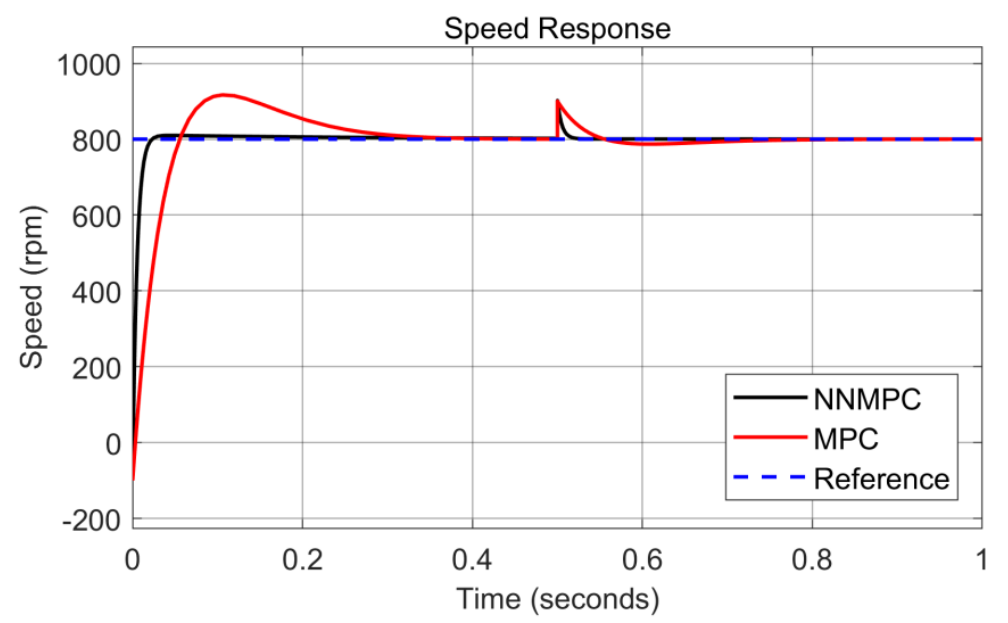

Figure 14. Speed response of the PMSM for sudden load change from $0.1 \mathrm{Nm}$ to $0 \mathrm{Nm}$

Fig. 13 shows the set point tracking results of the PMSM for sudden load change from $0 \mathrm{Nm}$ to $0.1 \mathrm{Nm}$ at 0.5 second. Model predictive controlled PMSM speed response has $11.25 \%$ undershoot, and settled at 0.67 seconds. Neural network model predictive controlled PMSM speed response has $4.35 \%$ undershoot and settled at 0.54 seconds. Fig. 14 shows the set point tracking results of the PMSM for sudden load change from $0.1 \mathrm{Nm}$ to $0 \mathrm{Nm}$ at 0.5 second. Model predictive controlled PMSM speed response has $11.5 \%$ overshoot, and settled at 0.68 seconds. Neural network model predictive controlled PMSM speed response has $5.1 \%$ overshoot and settled at 0.53 seconds. From the test results, it is observed that neural network model predictive controller has less overshoot, less undershoot and settled quickly. 


\section{CONCLUSION}

This paper presents speed control of the permanent magnet synchronous motor using neural network model predictive controller. The overall system has been simulated using MATLAB/Simulink software. Rigorous analyze of the proposed NNMPC and constrained MPC was studied. The Performance of neural network model predictive controller was compared with a constrained model predictive controller for the different operating conditions of the permanent magnet synchronous motor. From the test results, neural network model predictive controlled PMSM has overshoot of $0.11 \%$ to $5.1 \%$, undershoot of $0.12 \%$ to $4.35 \%$ and settling time of 30 to $40 \mathrm{~ms}$, but these parameters were not favor for model predictive controlled PMSM i.e. it has overshoot of $11.25 \%$ to $12.5 \%$, undershoot of $4.35 \%$ to 11.25 $\%$ and settling time of 170 to $300 \mathrm{~ms}$. As a result, neural network model predictive controller performs well in all aspect such as less overshoot, less undershoot and quick settling when compared with constrained MPC. Therefore, the proposed neural network model predictive controller suitable for speed control application of PMSM.

\section{REFERENCES}

[1] Cunha, G., Rossa, A.J., Alves, J.A., Cardoso, E., Control of permanent magnet synchronous machines for subsea applications, IEEE Transactions on Industry Applications, 2018, 54 (2), 1899-1905.

[2] Demir, Y., Aydin, M.,A novel dual three-phase permanent magnet synchronous motor with asymmetric stator winding, IEEE Transactions on Magnetics, 2016, 52(7), 1-5.

[3] Onsal, M., Demir, Y., Aydin, M., A new nine-phase permanent magnet synchronous motor with consequent pole rotor for high-power traction applications, IEEE Transactions on Magnetics, 2017, 53(11), 1-6.

[4] Wang, Z., Chen, J., Cheng, M., Chau, K.T., Field-oriented control and direct torque control for paralleled VSIs fed PMSM drives with variable switching frequencies, IEEE Transactions on Power Electronics, 2016, 31(3), 2417-2428, DOI:10.1109/TPEL.2015.2437893.

[5] Premkumar, K., Manikandan, B.V., Stability and performance analysis of anfis tuned pid based speed controller for brushless de motor, Current Signal Transduction Therapy, 2018, 13(1), 19-30.

[6] Mendoza - Mondragón, F., Hernández - Guzmán. V.M., Rodríguez-Reséndiz, J., Robust speed control of permanent magnet synchronous motors using two degrees of freedom control, IEEE Transactions on Industrial Electronics, 2018, 65(8), 6099-6108.

[7] Chang, Y.C., Chen, C.H., Zhu, Z.C., Huang Y.W., Speed control of the surface-mounted permanent-magnet synchronous motor based on takagi-sugeno fuzzy models, IEEE Transactions on Power Electronics, 2016, 31(9), 6504-6510.

[8] Zaihidee, F.M., Mekhilef, S., Mubin, M., Application of fractional order sliding mode control for speed control of permanent magnet synchronous motor, IEEE Access, 2019, 7, 101765-101774.

[9] Kim, S.K., Lee, J.S., Lee, K.B., Offset-free robust adaptive back-stepping speed control for uncertain permanent magnet synchronous motor, IEEE Transactions on Power Electronics, 2016, 31(10), 7065-7076.

[10] Chai, S., Wang, L., Rogers, E., Model predictive control of a permanent magnet synchronous motor with experimental validation, Control Engineering Practice, 2013, 21 (11), 1584-1593.

[11] Arehpanahi, M., Fazli, M., Position control improvement of permanent magnet motor using model predictive control, International Journal of Engineering transactions, 2018, 31(7), 1044-1049.

[12] Nguyen, A.T., Rafaq, M.S., Choi, H.H., Jung, J.W., A model reference adaptive control based speed controller for a surface-mounted permanent magnet synchronous motor drive, IEEE Transactions on Industrial Electronics ,2018 ,65(12), 9399-9409.

[13] Wu, B.F., Adaptive neural predictive control for permanent magnet synchronous motor systems with long delay time, IEEE Access, 2019, 7, 108061-108069. DOI10.1109/ACCESS.2019.2932746.

[14] Aguilar-Mejía, O., Tapia-Olvera, R., Valderrabano-González, A., Cambero, I.R., Adaptive neural network control of chaos in permanent magnet synchronous motor, Intelligent Automation and Soft Computing, 2016, 2(3), 499-507.

[15] Hadian, M., Mehrshadian, M., Karami, M., Makvand, A.B., Event-based neural network predictive controller application for a distillation column, Chinese Automatic Control Society and John Wiley \& Sons Australia, Ltd, 2019, 1-13. doi.org/10.1002/asjc.2265.

[16] Wang, L., Chai, S., Yoo, D., Gan, L., Ng, K., Discrete-time model predictive control (DMPC) of electrical drives and power converter, PID and Predictive Control of Electrical Drives and Power Converters using Matlab®/Simulink®, 2015.

[17] Wang, L., Chai, S., Yoo, D., Gan, L., Ng, K., MATLAB®/Simulink® Tutorials on physical modeling and test-bed setup, Wiley-IEEEPress, 2015, 315-337, DOI:10.1002/9781118339459. 
[18] Fasil, M., Antaloae, C., Mijatovic, N., Jensen, B.B., Holbolll, J., Improved dq-axes model of PMSM considering air gap flux harmonics and saturation, IEEE Transactions on Applied Super conductivity, 2016, 26(4), 1-5.

[19] Tarczewski, T., Grzesiak, L.M., Constrained state feedback speed control of PMSM based on model predictive approach, IEEE Transactions on Industrial Electronics,2016, 63(6), 3867-3875, DOI:10.1109/TIE.2015.2497302.

[20] Wang, W.C., Liu, T.H., Syaifudin, Y., Model predictive controller for a micro - PMSM - based five-finger control system, IEEE Transactions on Industrial Electronics, 2016, 63(6), 3666-3676, DOI:10.1109/TIE.2016.2543179.

[21] Formentini, A., AndrewTrentin, A., Marchesoni, M., Zanchetta, P., Speed finite control set model predictive control of a PMSM fed by matrix converter, IEEE Transactions on Industrial Electronics, 2015, 62(11), 6786-6796, DOI:10.1109/TIE.2015.2442526.

[22] Luo, Y., Liu, C., PMSM motor with a reduced-dimension cost function, IEEE Transactions on Industrial Electronics, 2019, 67(2), 969-979, DOI:10.1109/TIE.2019.2901636.

[23] Wang, F., Mei, X, Kennel, J.R.R., Model predictive control for electrical drive systems-an overview, Ces Transactions on Electrical Machines and Systems, 2017, 1(3), 219-230.

[24] Arashloo, R.S., Salehifar, M., Martinez, J.L.R., Andrade, F., Predictive dead beat current control of five-phase BLDC machines, IECON 2014 - 40 th Annual Conference of the IEEE Industrial Electronics Society, Dallas, TX, 2014, 30493053, doi: 10.1109/IECON.2014.7048944.

[25] Bolognani, S., Bolognani, S., Peretti, L., Zigliotto, M., Design and implementation of model predictive control for electrical motor drives, IEEE Transactions on Industrial Electronics, 2009, 56(6), 1925-1936.

[26] Ahmed, A.A., Koh, B.K. Lee, Y., A comparison of finite control set and continuous control set model predictive control schemes for speed control of induction motors, IEEE Transactions on Industrial Informatics, 2018, 14(4), 1334-1346, DOI:10.1109/TII.2017.2758393.

[27] Veksler, A., Johansen, T.A., Borrelli, F., Dynamic positioning with model predictive control, IEEE Transactions on Control Systems Technology, 2016, 24(4), 1340-1353, DOI:10.1109/TCST.2015.2497280.

[28] Tavernini, D., Metzler, M., Gruber, P., Sorniotti, A., Explicit nonlinear model predictive control for electric vehicle traction control, IEEE Transactions on Control Systems Technology, 2019, 27(4), 1438-1451, DOI:10.1109/TCST.2018.2837097.

[29] Zbede, Y.B., Gadoue, S.M., Atkinson, D.J., Model predictive MRAS estimator for sensorless induction motor drives, IEEE Transactions on Industrial Electronics, 2016, 63(6), 3511-3521, DOI:10.1109/TIE.2016.2521721.

[30] Wang, G., Qi, J., Xu, J., Zhang, X., Xu, D., Anti roll back control for gearless elevator traction machines adopting offsetfree model predictive control strategy, IEEE Transactions on Industrial Electronics, 2015, 62(10), 6194-6203, DOI:10.1109/TIE.2015.2431635.

[31] Arefi, M.M., Montazeri, A., Poshtan, J., Jahed-Motlagh, M.R., Wiener-neural identification and predictive control of a more realistic plug-flow tubular reactor, Chemical Engineering Journal, 2008, 138(1-3), 274-282.

[32] Kamaraj, P., Manikandan, B.V., Kumar, C.A., Antlion Algorithm Optimized Fuzzy PID Supervised On-line Recurrent Fuzzy Neural Network Based Controller for Brushless DC Motor, Electric Power Components and Systems, 2017, 45(20), 2304-2317.

[33] Csekő, L.H., Kvasnica, M., Lantos, B., Explicit MPC-based RBF neural network controller design with discrete-time actual kalman filter for semi active suspension, IEEE Transactions on Control Systems Technology, 2015, 23(5), 17361753, DOI:10.1109/TCST.2014.2382571.

[34] Mohamed, I.S., Rovetta, S., Do, T.D., Dragicević, T.,Diab, A.A.Z., A neural - network - based model predictive control of three - phase inverter with an output LCfilter, IEEE Access, 2019, 7, 124737-124749, DOI:10.1109/ACCESS.2019.2938220.

[35] Wang, T., Gao, H., Qiu, J., A combined adaptive neural network and nonlinear model predictive control for multi rate networked industrial process control, IEEE Transactions on Neural Networks and Learning Systems, 2016, 27(2), 416425, DOI:10.1109/TNNLS.2015.2411671.

[36] Cheng, L., Liu, W., Hou, Z.G., Yu, J., Tan, M., Neural - network -based nonlinear model predictive control for piezo electric actuators, IEEE Transactions on Industrial Electronics, 2015, 62(12), 7717-7727, DOI:10.1109/TIE.2015.2455026.

[37] Li, Z., Xiao, H., Yang, C., Zhao, Y., Model predictive control of nonholonomic chained systems using general projection neural networks optimization, IEEE Transactions on Systems, Man, and Cybernetics: Systems, 2015, 45(10), 1313-1321, DOI:10.1109/TSMC.2015.2398833.

[38] Liu, W., Cheng, L., Hou, Z.G., Yu, J., Tan, M., An inversion-free predictive controller for piezo electric actuators based on a dynamic linearized neural network model, IEEE/ASME Transactions on Mechatronics, 2016, 21(1), 214-226, DOI:10.1109/TMECH.2015.2431819.

[39] Xu, X., Chen, H., Lian, C., Li, D., Learning - Based predictive control for discrete-time nonlinear systems with stochastic disturbances, IEEE Transactions on Neural Networks and Learning Systems, 2018, 29(12), 6202-6213, DOI:10.1109/TNNLS.2018.2820019.

[40] Yoon, S., Jeon, H., Kum, D., Predictive cruise control using radial basis function network - based vehicle motion prediction and chance constrained model predictive control, IEEE Transactions on Intelligent Transportation Systems, 2019, 20(10), 3832-3843, DOI:10.1109/TITS.2019.2928217. 
[41] Akesson, B.M., Toivonen, H.T., A neural network model predictive controller, Journal of Process Control, Elsevier, 2006, 16(9), 937-946.

[42] San, O., Maulik, R., Neural network closures for nonlinear model order reduction, Advances in Computational Mathematics, 2018, 1717-1750.

[43] Kassem, A.M., Neural predictive controller of a two-area load frequency control for inter connected power system, Ain Shams Engineering Journal, 2010, 1, 49-58. 